
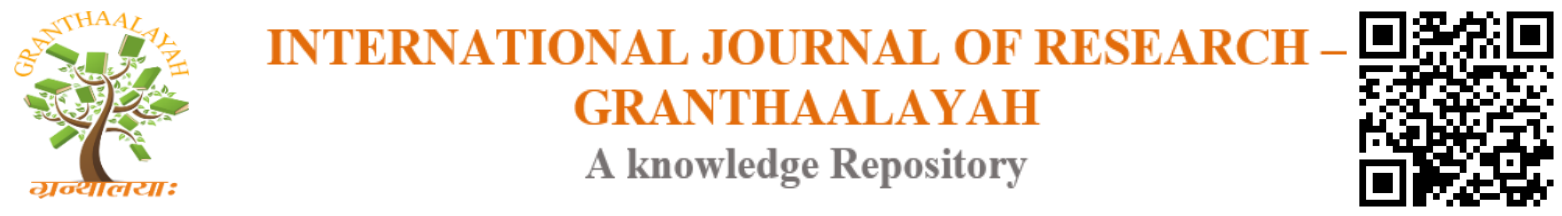

Social

\title{
EXPLORINGTHE PREPAREDNESS OF FAMILY CARE GIVERS TO PROVIDE CANCER PALLIATIVE CARE
}

\author{
MKD Lalitha Meegoda ${ }^{1}$, Sharaine Fernando ${ }^{2}$, S Sivayogan ${ }^{3}$, NOS Atulomah ${ }^{4}$ \\ ${ }^{1}$ Senior Lecturer, B.Sc. Nursing Programme, Department of Allied Health Sciences \\ ${ }^{2}$ Professor in Physiology, Department of Physiology, University of Sri Jayewardenepura, Sri \\ Lanka \\ ${ }^{3}$ Emeritus Professor, University of Sri Jayewardenepura, Sri Lanka \\ ${ }^{4}$ Professor of Health Promotion, Babcock University, Nigeria
}

\begin{abstract}
Background: Palliative care for pain relief and management of other distressing symptoms of cancer patients specially through non-pharmacological approach by family care givers (FCGs) improves the quality of life of patients. Preparedness of FCGs for this role needs to be explored.

Methodology: Descriptive qualitative design was adopted to explore the FCGs readiness on providing cancer palliative care for their cancer survivors. Focus Group Discussions were conducted in public sector, private sector and cancer care institutions which are managed by the Cancer Society in the Colombo area until data saturation was achieved between September 2011 to January 2012.

Results: Most of the FCGs were females and the mean (SD) age was $39( \pm 10)$ years. The average educational level of the FCGs/domiciliary care providers was at primary level. Thematic analysis of their data on the readiness to provide cancer PC emerged four key themes; readiness in providing care, need relaxation, need psychosocial support and inadequate knowledge.

Conclusion: FCGs had the readiness to provide care for their patients amidst challenges they face during the time of care giving. Family care givers were of the view that having knowledge and experience as an FCG will facilitate in continuing to care effectively.
\end{abstract}

Keywords: Family Care Givers; Non-Pharmacological Approach; Cancer Palliative Care.

Cite This Article: MKD Lalitha Meegoda, Sharaine Fernando, S Sivayogan, and NOS Atulomah. (2019). "EXPLORINGTHE PREPAREDNESS OF FAMILY CARE GIVERS TO PROVIDE CANCER PALLIATIVE CARE." International Journal of Research - Granthaalayah, 7(6), 18-26. https://doi.org/10.29121/granthaalayah.v7.i6.2019.734.

\section{Introduction}

There is a rapid rise in adult cancers of all types in Sri Lanka (Ministry of Health, 2015). Number of newly registered patients at government cancer units in 2012 was 11,163 (Ministry of Health, 2012). According to the World Health Organization (WHO, 2007), Sri Lanka ranks the highest in 
non-communicable diseases (NCDs) in Southeast Asia. Sri Lanka's cancer trend is similar to that of Western countries (WHO, 2007) and the second leading cause of death in Sri Lanka, is neoplasms (Ministry of Health, 2015).

Majority of cancer patients worldwide are in advanced stages of cancer at the time of diagnosis (Cancer News Center, 2008). For them, pain relief and palliative care are the two main aspects of management although the needs vary significantly between patients. Presently, caregivers, especially in low and middle income countries, are challenged with providing quality care due to shortage in manpower and limited training opportunities to equip with the skills required to meet the challenge (WHO, 2007). Although 57\% percent of cancer patients died at the cancer centers after admission (Azvolinsky, 2015) more than 65\% of cancer patients survive for more than five years. Therefore, quality-of-life issues of cancer patients and their families continue even after active treatment is completed (American Cancer Society, 2010). Many investigators have shown the importance of providing palliative care services for cancer patients (Chilton, 2003) and its importance to improve patients' quality of life (Singh, 2010). Palliative care (PC) is a system of care given to a terminally ill person involving a holistic approach to meet the physical, psychological, emotional and spiritual needs of the patient (Kristjanson et al., 2008). The basic philosophy of palliative care is to achieve the best quality of life for patients even when their illness cannot be cured (WHO, 2007). It is an approach that improves the quality of life of patients and their families facing the problems associated with life threatening illness, through prevention and relief of suffering, with early identification and perfect assessment and treatment of pain and other symptoms (WHO, 2007).

In Sri Lanka, limited access to palliative care services makes it difficult for patients and their families to go through the phases of disease and dying. Lack of health professionals trained to deliver palliative and end-of-life care services compounds the problem. Similar shortfalls in infrastructure and personnel have been reported even in high income countries like USA and Germany (Grant et al., 2009, Schneider et al., 2010). To overcome the problem of care giving some hospitals permit domiciliary care providers/family care givers (DCPs) to stay with the patients and assist at the bedside. DCPs are individuals who provide uncompensated care or support to a family member who is suffering from several symptoms (Given, 2011). Family care givers (FCGs) take a dynamic role from the time of diagnosis of cancer. However, FCGs often are unprepared to deliver care (Scherbring, 2002). The unpreparedness leads to inadequate knowledge to deliver appropriate care. Furthermore, they receive little guidance from the formal health care providers (Scherbring, 2002) to maintain quality of life of the patients. When the caregiver is trained in how to help the patient to manage side effects of treatment and symptoms such as pain and fatigue, the patient is more likely to have compliance with treatment (NCI, 2013). Palliative care provided either by nurses or DCPs improves the quality of life of patients and their families facing lifethreatening illness by providing pain relief and management of other distressing and unbearable symptoms (WHO, 2007). Readiness of care givers to provide care for the patients is crucial in providing quality care. This study was conducted to assess the readiness of DCPs and to describe their views on providing care to cancer patients in three main cancer care providing institutions in Sri Lanka. 


\section{Methodology}

Descriptive qualitative design was adopted to explore the DCPs/FCGs views on providing cancer palliative care for their cancer survivors. One FGD each for the DCPs in the public sector, private sector and the institutions which are managed by the Cancer Society were conducted until data saturation was achieved (a total of three FGDs) between September 2011 to January 2012.

When selecting DCPs for the focus group discussion similar proportions of males and females were included, but educational and socioeconomic backgrounds were not considered. Semistructured interviewer guide was used to identify factors affecting readiness to provide care. Data from each FGD were recorded (Data evidence) and saved in a digital voice recorder which could be easily transferred to a computer.

Max Van Manen's Phenominological approach was followed to analyze qualitative data. DCPs lived experience on palliative care was collected to come to a fuller grasp of what it means to be in the human world (Van Manen, 2001). When analyzing data from FGDs an identification number was given to each participant as DCP-1 to DCP-15. All the recorded data were replayed. The interviews were transcribed verbatim. Each written transcript was read several times while listening to the corresponding audio tape to ensure accuracy of the transcribed record and to come to a better overall understanding of each participant's experience. The significant statements and ideas of each transcript were highlighted to identify the thematic areas. Phrases with similar meaning were taken separately. Themes were identified by manual coding and thematic analysis was performed.

Approval was obtained from the Ministry of Health to conduct the study at National Institute of Cancer Maharagama (NICM). Ethical approval was obtained from the Ethical Committee of the NICM and Ethics Review Committee of University of Sri Jayewardenepura. Participants were made aware of the voluntary nature of their participation. Confidentiality and anonymity of the information were maintained. To ensure the trustworthiness of the qualitative studies Guba's model in Krefting (1990) was used. Guba's model is based on identification of four aspects which are credibility, transferability, consistency and neutrality. Rigour was enhanced through these four aspects.

\section{Results}

\section{Focus Group Discussions with Domiciliary Care Providers}

Most of the FCGs were females and the mean (SD) age was $39( \pm 10)$ years. The average educational level of the FCGs/domiciliary care providers was at primary level. Thematic analysis of their data on the readiness to provide cancer PC emerged four key themes; readiness in providing care, need relaxation, need psychosocial support and inadequate knowledge. DCPs at the selected institutions have understood patients' needs; they appreciated patients' effort to get cured. As DCPs are one of the most stressed categories, they needed relaxation while providing care. Despite having their own psychosocial problems, the DCP's were concerned with providing psychosocial support to their patients. DCPs expressed that they need to gain knowledge on the patient's disease condition to provide better care. 


\section{Readiness in Providing Care}

"I provide care willingly. Whenever she needs my help I help her. We have to strengthen patient's mind. I always think I have to be with her for her psychological support" (DCP 12, FGD-3).

"We are from far away. We have financial problems as well, but we cannot reveal the financial problems to the patient. So sometimes we are helpless when providing care” (DCP-2, FGD-1).

DCPs readily provided care to their patients. Some DCPs told that they needed money to buy medicine when the required medicine was not available in the hospital. They had transport problems as well, since they lived far away from the hospital.

"We were advised from the ward to give more fluids. When I give more fluids he gets angry with me. He did not get that much angry earlier. I can understand his emotional situation" (DCP 15, FGD-3).

"She always wants to talk with me about her worries. So, I talk with her because we have to understand her need to express these worries" (DCP-3, FGD-1).

Patients had different kinds of losses due to the disease condition. Therefore, most of the DCPs were of the opinion that patients had to talk with them frequently.

"Sometimes I chant pirith (Religious) to my father, because he is not in a position to say pirith. He listens well and consciously. By looking at his face while saying pirith I feel happy (smiling)" (DCP-5, FGD-1).

"My family members and I am satisfied with the care I provide" (DCP-8, FGD-2).

Palliative care includes physical, psychological and spiritual support to the patient with concerns of communication and with support of the family members. Different DCPs ready to provide different aspects of the care including spiritual aspects.

\section{Seek Psychosocial Support}

"Patients conditions vary. So we have to listen to doctors, nurses and other health care workers about patients care, because they are the ones who know the patient well. This is my son, he was to sit the Advanced Level examination next year (tears). I expect him to be cured soon so that he can sit the Advanced Level examination" (DCP-2, FGD-1).

"There are some people even in the hospital who talks about 'cancer patients", I feel the name called 'cancer patients' should be changed" (DCP-14, FGD-2).

DCPs had varying expectations with regards to patients cure and they apply the best under the circumstances.

"My son has lots of friends. Friends and relatives visit him regularly. He had a girlfriend. Earlier we did not agree to that relationship. Now I allow her to visit him, because my son appears very happy when she visits him. I want to keep him happy now" (DCP - 3, FGD-1). 
"I did a job. I gave it up, because of my father. Doctors say that he has limited time. So I want to look after him well during this short period. I can find another job later" (DCP-6, FGD-2)). Family members of patients experience varying psychosocial problems while caring for their patients. However DCPs desired to figure out how to provide care in a holistic manner and wanted to deliver the best to their patients despite their own problems.

"She worries because I am not married. I told her not to worry about me and I am strong enough to face any challenge. She is thinking about my father, because he has heart disease. My problem is I don't have leave of absence from work to look after her. If I am unable to give adequate care to her I feel depressed. To give care to these patients we need a strong mind" (DCP-8, FGD-2). DCPs continue providing care with no previous experience which is not the best with regards to palliative care.

\section{Need Relaxation}

"I was with my daughter in this ward for two weeks. I cannot go home while she is suffering on the bed here. If I can be with her I can help her as much as I can. She was studying for her O/Level examination. I want her cured before the examination to enable her to sit for it. I do not want to have relaxation (tears). I can get rest when she sleeps with pain relief" (DCP-9, FGD-2).

"We do not have time to watch TV. We do not have time to read. Because while staying with the patient we always think how to help the patient, what is the condition of the patient and so on. I do not have a place or opportunity to get rest, but it's ok. I have to devote my time for my sister. My sister is waiting to do a job because she was doing her BA (Bachelor of Arts) degree when she started getting symptoms" (DCP - 13, FGD-3).

"If there is an awareness programme about the disease condition, relaxation techniques and exercises, for our patients it is good to maintain patients' quality of life" (DCP - 15, FGD-3).

According to the DCPs views not only their patients but family care givers also need relaxation. They emphasized that relaxation would increase the readiness to provide the care.

"We give care amidst lots of difficulties. I have my own daughter and son to look after. My mother looks after them (pause and sighed). I have heard about Ayurvedic methods which have power to cure this kind of conditions. Do you know about them?

DCPs have family problems too. DCPs believe the patients need more help continuously, so despite the other family issues DCPs do not like to give up on meeting the patient's expectations. Family care givers seek alternative/complimentary methods to get their patients cured.

\section{Inadequate knowledge}

"We have to identify patient's needs to give relevant care. She is my mother and I have been giving her care for five years. When she complains of pain I rub there, I prepare meals, orange and eggs for her, but still I need more knowledge to provide better care, I give care through experience. I don't know the exact methods for pain reduction which is essential" (DCP - 7, FGD-2). 
"I do not have any training on patient care. I do not have experience either. I just help her when she asks some help like feeding, washing, grooming and toileting". Otherwise always I seek advice from the doctors or nurses (When I cannot give adequatecare to her I feel unhappy. DCP - 1, FGD-1).

Most DCPs did not have enough experience to identify the patient's needs. They provided care with current experience, because the patients are their own family members.

"We think patient's sleep is not more important than medicines. We have to identify their needs and provide care accordingly. When she has difficulty in breathing, I can identify it and raise her head and then inform nurses. I was not given information regarding her care anyway" (DCP $10, F G D-2$ ).

DCPs revealed even in the absence of basic facilities like a place to have proper sleep, time to get rest, psychological support and basic knowledge on palliative care, they continue to care because of the concern for patients.

\section{Discussion}

Needs and capabilities of DCPs are influenced by factors such as gender, age, education, financial status, and geographical location (Given, 2011). In the current study most of the DCPs were females and the mean (SD) age was $39( \pm 10)$ years. The average educational level of the domiciliary care providers was at primary level. Despite this there was a positive attitude of DCPs towards providing care for their patients. Though most of the DCP's were not adequately knowledgeable on palliative care and were not experienced in providing care, they did so very willingly. The reason for this could be that in the current study, the DCPs were patients' family members (Meegoda, et al. 2018) and the patients too were satisfied with the assistance given by the DCPs. It was found that despite not having a medical background, daily contact with the patient gives the caregiver important information that help the patient (Meegoda, et al. 2018)

DCPs in the current study revealed that psychological, religious and financial support was crucial when providing care to the patients. In the current study one of the DCPs gave up his job to care for the patient. However, the impact of such decisions would be on the whole family. DCPs believed in the need to reciprocate the love and care given by the patients when they were well and the DCPs did so compromising their own psychological problems. This could be at the expense of their own health. As reported in the he study conducted in NICM, Sri Lanka, the family care givers believed that all their patients were satisfied with the care they provided and $95 \%$ believed that they had to be with the patient always (Meegoda et al., 2015) Schulz and Beach (1999) reported similar findings that caregivers often neglect their own health care needs in order to assist the family member, causing deterioration in the caregiver's health and well-being.

DCPs too need relaxation, but in the institutions where this study was conducted, the facilities available for relaxation were minimal. Basic facilities to have adequate sleep were not provided in these institutions. Similar results have been reported by Kulkarni et al., (2014) where a large number of caregivers in Cipla Palliative Care Center in India reported feeling continually tired and exhausted. Reinhard et al. (2008) also reported that the work of family caregiving can be stressful. 
Stress can adversely affect both the caregiver and the care recipient. Hence upgrading facilities for DCP's to rest and relax in the institutions where the cancer patients are hospitalized is recommended as a measure of improving overall care.

Domiciliary care providers also expressed the desire for knowledge on palliative care, as the immediate contact with the patients and the long term commitment. This was reported previously as DCPs were aware of several ways to deliver care however, $94 \%$ of them felt the need to gain more knowledge about palliative care and $62 \%$ of DCPs had no previous experience in providing palliative care to their patients (Meegoda et al., 2015). This has been emphasized by others. Scherbring (2002) reported that family care givers often feel unprepared to provide care, have inadequate knowledge to deliver proper care and receive little guidance from the formal health care providers. In a similar study done by Michael et.al. (2013) DCPs expressed the need for professional support to help the patients, as they have not received any training. Due to inadequate knowledge and skills, family caregivers may be incompetent with the type of care and the quantum of care needed (Reinhard et al., 2008). Freedom to provide care and resources were most important, because DCP's provide care willingly. DCPs expect to gain knowledge on cancer palliative care from the health system. As evident by the results of the current study and those reported by others, educating the care providers is imperative in creating readiness to provide quality of care.

The DCPs desired to know the appropriate way to provide care in a holistic manner and desired to provide the best to their patients despite their own problems. In a qualitative systematic review of thirty-four studies from eight different countries was conducted by Docherty et.al. (2008) to identify knowledge and information needs of informal caregivers in palliative care it was found the strongest evidence in relation to importance of care givers education. According to the DCPs in the current study patients were enthusiastic to know about alternative treatment options for symptom relief. Cancer patients tend to seek complementary and alternative healing methods for their disease related symptoms and side effects experienced due to western medicine (Mansky \& Wallerstedt, 2006; De Silva et al., 2008). As an answer for this issue Nimmaanratet et al. (2010) highlighted poor knowledge and misconceptions with regard to cancer pain and its management essentially need to be corrected, since they can lead to ineffective cancer pain relief.

\section{Conclusion}

In this study conducted among three main institutions providing care to cancer patients in Sri Lanka the FCGs had the readiness to provide care for their patients amidst challenges they face during the time of care giving. DCPs were of the opinion that psychological support and relaxation during the stay with the patients will be beneficial to performing their role well. Family care givers were of the view that having knowledge and experience as a DCP will facilitate in continuing to care effectively.

\section{Acknowledgement}

University Research Grant (ASP/06/Re/2009/09 Of 10/12/2008) - University of Sri Jayewardenepura, Sri Lanka. 


\section{References}

[1] American Cancer Society. (2010) Cancer facts \& figures Atlanta, GA: American Cancer Society; 2010 [cited 2011 Mar 15]. Available from:

http://www.cancer.org/Research/CancerFactsFigures/CancerFactsFigures/cancer-facts-andfigures-2010.Chilton, 2003

[2] Azvolinsky, A. (2015). Eight signs death is imminent in advanced cancer patients. Network, home of the journal Oncology.

[3] Cancer News Center, "Programme of action for cancer therapy. [Accessed 23, May 2008]," 2008.

[4] De Silva, B.S.S., Rolls, C. and Campbell, M. (2008) An ethnography study of nurses: Cancer pain management in Sri Lanka. Thesis Submitted to Australian Catholic University, Australia http://dlibrary.acu.edu.au/digitaltheses/public/adt-acuvp227.14012010/02whole.pdf.

[5] Docherty, A., Worcestershire, PCT, Owens, A. Asadi-Lari, M., Petchey, R. Williams, J. and Carter, Y. (2008). Knowledge and information needs of informal caregivers in palliative care: a qualitative systematic review. Journal of Palliative Medicine SAGE Publications, Los Angeles, London, New Delhi and Singapore. 1-19

[6] Given B. A., Sherwood P., and Given C. W., "Support for caregivers of cancer patients: Transition after active treatment," American Association for Cancer Research, vol. 20, pp. 2015-2021, 2011. View at Google Scholar | View at Publisher

[7] Grant, M., Elk, R., Ferrell, B., Morrison, R. S., and. Gunten, C. F, "Current status of palliative careclinical implementation, education and research," Cancer Journal for Clinicians, vol. 59, pp. 327335, 2009. View at Google Scholar

[8] Kristjanson et al., 2008) education: Australian \& Canadian challenges," Journal of Contemporary Nurse, vol. 6, p. 950, 2008.

[9] Kulkarni, P., Kulkarni, P, Ghooi, R, Bhatwadekar M, Thatte N. and Anavkar, V. "Stress among care givers: The impact of nursing a relative with cancer," Indian Journal of Palliative Care, vol. 20, pp. 31-39, 2014. View at Google Scholar | View at Publisher

[10] Mansky, P.J., and Wallerstedt, D.B. (2006). Complementary Medicine in Palliative Care and Cancer Symptom Management. Cancer Journal, 12(5), 425-431.

[11] Meegoda MKDL \& Fernando DMS \& Sivayogan S \& Atulomah, NOS \& Marasinghe, RB, 2018. "Domiciliary Care Providers Views on Provision of Palliative Care for their Cancer Patients," Cancers Review ISSN(e): 2408-9273, Conscientia Beam, Asian Medical Journals. vol. 4(1), pages 1-7. DOI: 10.18488/journal.95.2018.41.1.7

[12] Meegoda L, Fernando S, Sivayogan S, Atulomah NO, Jayasiri J. Perceived palliative care needs of cancer patients, nurses and domiciliary care providers at a national cancer referral facility, Sri Lanka. Journal of Pioneer Medical Sciences. 2015; 5(2):46-50

[13] Michael, N., O'Callaghan, C. and Hiscock, N. (2013). Cancer Caregivers Advocate a Patient- and Family-Centered Approach to Advance Care Planning. Journal of Pain and Symptom Management 47 (6) Pages, 1064-1077.

[14] Ministry of Health. 2015, Cancer incidence data, Sri Lanka. National Cancer Control Programme.

[15] Ministry of Health. (2012) Annual Health Bulletin Sri Lanka: Medical Statistics Unit.

[16] National Cancer Institute (2013). Family care givers in Cancer. U.S. Department of Health Homan Services, USA Government.

[17] Nimmaanrat, S., Prechawai, C. and Phungrassami, T. (2010) Cancer pain and its management: A survey on interns knowledge, attitudes and barriers. Palliative care Research and Treatment.4. 1117. Available at: http://www.la-pres.com.

[18] Reinhard, S.C., Given, B., Petlick, N.H. and Bemis,A. (2008). Supporting Family Caregivers in Providing Care. Chapter 14. Patient safety and quality; An evidence-based handbook for nurses by Hughes, April 2008. 
[19] Scherbring, M. "Effect of caregiver perception of preparedness on burden in an oncology population," Oncology Nurses Forum, vol. 29, pp. E70-E76, 2002. View at Google Scholar | View at Publisher

[20] Schneider, N., Mitchell, G.K., Murray, S.A. (2010). Palliative care in urgent need of recognition and development in general practice: The examples of Germany. BMC Fam Pract. 11:66. [PMC free article] [PubMed]Singh, D. P. (2010). Quality life in Cancer patients receiving palliative care. Indian journal of palliative care. 16(1). p.36-43.

[21] Schulz, R. and Beach, S.R. Caregiving as a risk factor for mortality: The caregiver health effects study. JAMA.1999;282:2215-9. [PubMed]

[22] Van Manen M. (2001). Researching lived Experience: Human Science for An Action Sensitive Pedagogy. The University of Western Ontario London.

[23] World Health Organization (WHO), Cancer control knowledge into action. WHO Library cataloguing in publication data. 2007. Available at:

http://www.who.int/mediacentre.news/notes/2007

\footnotetext{
*Corresponding author.

E-mail address: meegodal@yahoo.com
} 